\title{
COMPARATIVE MEASUREMENTS OF MEMBRANE POTENTIALS WITH MICROELECTRODES AND VOLTAGE-SENSITIVE DYES
}

\author{
THOMAS BRÄUNER, DIETER F. HÜLSER * and RETO J. STRASSER \\ Biologisches Institut, Universität Stuttgart, Ulmer Str, 227, D.7000 Stuttgart-60 (F.R.G.)
}

(Received August 18th, 1983)

(Revised manuscript received December 7th, 1983)

Key words: Membrane potential; Voltage -sensitive dye; Cell culture; Fluorescent dye; Cell fusion; Voltage clamp

The usefulness of a new voltage-sensitive fluorescent dye, the membrane permeant negatively charged oxonol dye diBA- $\mathrm{C}_{4}-(3)^{-}$, was evaluated by measuring the membrane potentials of BICR/M1R-k and $L$ cells with glass microelectrodes and simultaneously recording the fluorescence of the stained cells. The membrane potential of BICR/M1R-k cells was varied between $-25 \mathrm{mV}$ and $-90 \mathrm{mV}$ by changing the bicarbonate concentration in the medium or by voltage clamping. To avoid any interference by the inserted electrodes with the fluorescence measurement of the cytoplasm, the cells were fused by polyethyleneglycol to form giant cells (homokaryons). These homokaryons also allowed penetration by two glass microelectrodes without causing a serious leakage of the plasma membrane. The slow responding dye $\operatorname{diBA}-\mathrm{C}_{4}-(3)^{-}$had a fluorescence response of about $1 \%$ per $\mathrm{mV}$. Mathematical analysis of the fluorescence changes after voltage clamping revealed a first-order reaction with a rate constant between $0.1 \mathrm{~min}^{-1}$ and $0.8 \mathrm{~min}^{-1}$, depending on the cell size which was determined by the number of nuclei per homokaryon. A model for the mechanism of the fluorescence changes is proposed.

\section{Introduction}

Measurements of membrane potentials with glass microelectrodes face some difficulties when delicate cells are the subject of the impalement. Delicate cells can be those in which the membrane does not seal properly around the electrode glass, they may be small like lymphocytes where the microelectrode tip is relatively too large, big like sea urchin eggs but easily activated by electrode impalement.

These problems can partly be solved when 'whole cell' recordings with patch clamp electrodes are performed [1]. The risk of electrical and mechanical activation still remains. Application of non-toxic voltage-sensitive fluorescent dyes seems

\footnotetext{
* To whom correspondence should be addressed.
}

to be the least damaging method for the determination of membrane potential changes; absolute measurements, however, are not yet routinely available.

Optical methods of measuring membrane potentials were introduced by Cohen et al. [2]. In the meantime, more than 1000 dyes have been tested for their ability to indicate membrane potential changes [3]. The potential-sensitive probes split mainly into three classes of polymethine dyes; merocyanines, cyanines and oxonols. However, they are often classified by the velocity with which they respond to changes of membrane potential. Siowly responding dyes need seconds to minutes until a new plateau of fluorescence signal is reached, its amplitude may well exceed $80 \%$. Fast dyes respond within microseconds, their signal amplitude changes less than 1\%. For a review 
see Waggoner [4] and Freedman and Larris [5]. The slowly responding oxonol dyes contain a delocalized negative charge which makes them permeant to cell membranes [6]. The charged dye molecules probably undergo a potential-dependent distribution between the cytoplasm and the extracellular medium. Sims et al. [7] have described a mechanism by which cyanine dyes respond to changes of the membrane potential: these permeant probes have a delocalized positive charge which enables membrane permeation and a membrane potential-dependent distribution of the dye. Hyperpolarization causes intracellular dye accumulation resulting in a formation of dye dimers and larger aggregates which are less fluorescent. Cell depolarization results in dye partition to the extracellular medium where, due to the lower dye concentration, the predominating dye monomers are responsible for the increase in fluorescence intensity. For these cyanine dyes, a standard procedure has been developed using $\mathrm{K}^{+}$ionophores and different $\mathrm{K}^{+}$concentrations in the medium for obtaining different membrane potential levels which allowed a correlation of the optical signals to a calculated membrane potential change [7-9]. This procedure gives mean values of the potential changes in a suspension culture by spectrofluorimetry of the supernatant medium or the cell suspension. Slowly responding oxonol dyes have not been used with cell suspensions because these negatively charged molecules form complexes with many ionophores and, therefore, resist the above-mentioned calibration method for potential changes [6].

In this paper, we describe a direct calibration method with a commercially available epifluorescent illumination microscope and established electrophysiological measurements with glass microelectrodes. The fluorescence signal of an individual cell loaded with slowly responding dyes was measured simultaneously together with the membrane potential of the same cell. With this set-up, cyanine-dye-loaded monolayer cells did not respond to voltage clamping with significant changes in fluorescence intensity. However, this direct calibration method revealed the usefulness of oxonol dyes when the cytoplasmic fluorescence is used as a quantitative signal for membrane potentials. Mathematical analysis of voltage clamp ex- periments resulted in first-order kinetic, for the changes in fluorescence intensity.

\section{Material and Methods}

Cell cultures. Rat mammary tumor cells BICR/M1R- $k$ - and mouse embryo cells - L were cultured at $37^{\circ} \mathrm{C}$ in modified Eagle-Dulbecco medium [10] with $5 \%$ calf serum and were regulated at $\mathrm{pH} 7.2$ with an atmosphere of $5 \% \mathrm{CO}_{2}$ in air. The cells were grown to confluency in plastic Petri dishes (Falcon or Greiner) and treated with $40 \%(\mathrm{w} / \mathrm{w})$ polyethyleneglycol (mol. wt. 1540, Koch Light) for 1-4 min. The following incubation at $37^{\circ} \mathrm{C}$ in medium led within $4 \mathrm{~h}$ to the formation of homokaryons with different amounts of nuclei [11]. To avoid background fluorescence, the electrophysiological and fluorescence measuring experiments were performed in phosphatebuffered saline.

Electrophysiology. Membrane-potential recordings were performed with Leitz micromanipulators and glass microelectrodes filled with $3 \mathrm{M} \mathrm{KCl}$ (Hilgenberg Glas with inner filament) which had tip potentials below $-5 \mathrm{mV}$ and resistances ranging from 20 to $40 \mathrm{M} \Omega$ in the standard medium. The potential differences were measured with a high-input impedance preamplifier (WPI, model $M$ 701) and varied by injecting current through a second electrode connected to a generator (Stimulator P, Hugo Sachs Elektronik). The cells were observed at room temperature under an Ortholux II microscope (Leitz) equipped with an electrically insulated $40 \times$ water immersion objective (Zeiss $40 / 0.75 \mathrm{~W}$ ).

Fluorescence measurements. The Ortholux II microscope was equipped with a binocular phototube FSA and two lamp housings: type 50 with a halogen lamp (12 V, $50 \mathrm{~W})$ for phase-contrast observations and type $100 \mathrm{Z}$ with a xenon lamp (75 W) operated with a dc source (type 301-206). The epifluorescence illuminator Ploemopak 2.2 was equipped with the Leitz filter system I: exciter filter $2 \times \mathrm{KP} 490,1 \mathrm{~mm}$ GG 455; dichroic mirror TK 510; barrier filter K 515. To prevent rapid bleaching of the fluorescent preparations, a neutral density filter reduced the light intensity of the xenon lamp to about $25 \%$. A photomultiplier (RCA $1 \mathrm{P} \mathrm{28)}$ was mounted to the phototube via a mi- 


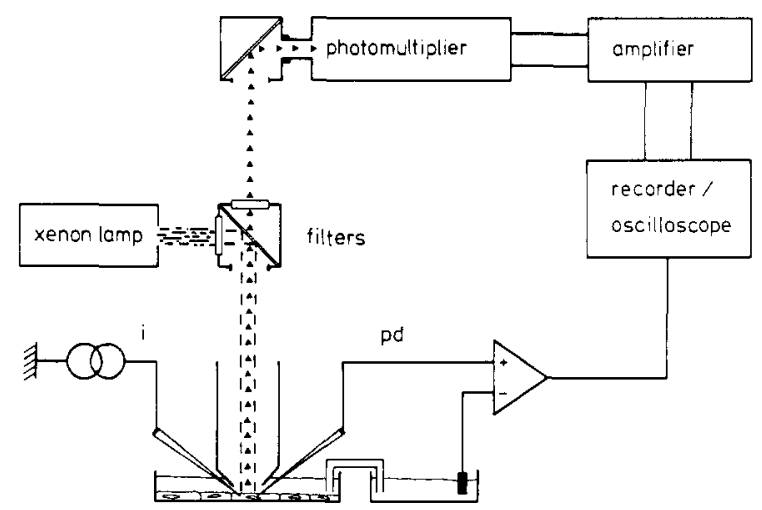

Fig. 1. Experimental set-up for simultaneous measurements of membrane potential and fluorescence intensity in single cells or homokaryons of a monolayer culture.

crophoto adapter (Kavar, Leitz). The phototube was fitted with a $10 \times$ Periplan ocular, in which a $1.5 \mathrm{~mm}$ aperture was centered in the focal plane of the real image of the object. This allowed a controlled selection of single cells or areas from a homokaryon for the determination of fluorescence intensity. A schematic drawing of our experimental set-up is shown in Fig. 1 .

Voltage sensitive dye. In this paper we concentrate exclusively on the negatively charged fluorescent oxonol dye diBA- $\mathrm{C}_{4}-(3)^{-}$which was kindly provided by Dr. A.S. Waggoner. It exhibited the highest voltage sensitivity from all tested substances and was found the most suitable for the optical set-up.

The negatively charged diBA-C $4^{-(3)}$ (bis(1,3dibutylbarbituric acid-(5))trimethineoxonol) has a molecular weight of 516.4. A $1 \mathrm{mM}$ stock solution in ethanol was stored in foil-wrapped tubes in a refrigerator, without noticeable loss of sensitivity, for several weeks. For the calibration experiments, the cells were incubated at $37^{\circ} \mathrm{C}$ in phosphatebuffered saline, containing different bicarbonate concentrations $30-60 \mathrm{~min}$ before the measurements. $20 \mathrm{~min}$ prior to the fluorescence measurements dye was added to a final concentration of 2 $\mu \mathrm{M}$. The stained cells were used for the experiments under the microscope without washing.

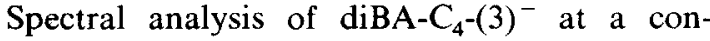
centration of $2 \mu \mathrm{M}$ in phosphate-buffered saline revealed maximum emission at a wavelength of $517 \mathrm{~nm}$, as measured in a Perkin-Elmer fluorescence spectral photometer (MPF-3L). This wave- length is in the region of $50-60 \%$ of the maximum sensitivity (about $340 \mathrm{~nm}$ ) of the used photomultiplier. In an Aminco spectral photometer (DW-2a) the maximum of absorption was registered at 495 $\mathrm{nm}$.

Mathematical analysis of the experimental data was performed with an Imsai 8080 Microcomputer (IMS Assoc., U.S.A.).

\section{Results}

Fig. 2 shows phase contrast pictures of monolayers of the investigated cell lines BICR/M1R-k and $\mathrm{L}$ as well as polyethyleneglycol-induced fusions of these cells and the same homokaryons stained with the oxonol dye diBA- $\mathrm{C}_{4}-(3)^{-}$. Background fluorescence was drastically reduced when serum-free medium was used. Therefore, the cells were washed with serum-free medium and all fluorescence measurements were performed in phosphate-buffered saline. Note that the nuclei are not stained and the fluorescence intensity of the cytoplasm varies considerably.

To investigate the correlation between the fluorescence intensity and the electrode-determined membrane potential of BICR/M1R- $k$ homokaryons, different bicarbonate concentrations were added to the phosphate-buffered saline in order to change the membrane potential of the whole cell population [12]. These medium-induced changes of the membrane potential covered a range of -25 $\mathrm{mV}$ to $-90 \mathrm{mV}$. In Table $\mathrm{I}$, the data for three different membrane potential levels and their respective fluorescence intensity signals are listed for $\mathrm{BICR} / \mathrm{M} 1 \mathrm{R}-k$ homokaryons.

Regression analysis of about 1700 measurements of BICR/M1R- $k$-homokaryons in phosphate-buffered saline with different bicarbonate concentrations resulted in a slope of $-0.43 \pm 0.12$, indicating a decrease of the relative fluorescence signal with increasing potential difference.

The time-course of the fluorescence change was determined by inserting two electrodes into one cell, which allowed potential measurements and voltage clamping with both hyper- and depolarizing steps. A typical experiment for a L-homokaryon is shown in Fig. 3.

The homokaryon's membrane potential of about $-30 \mathrm{mV}$ gave a fluorescence signal of about 65 

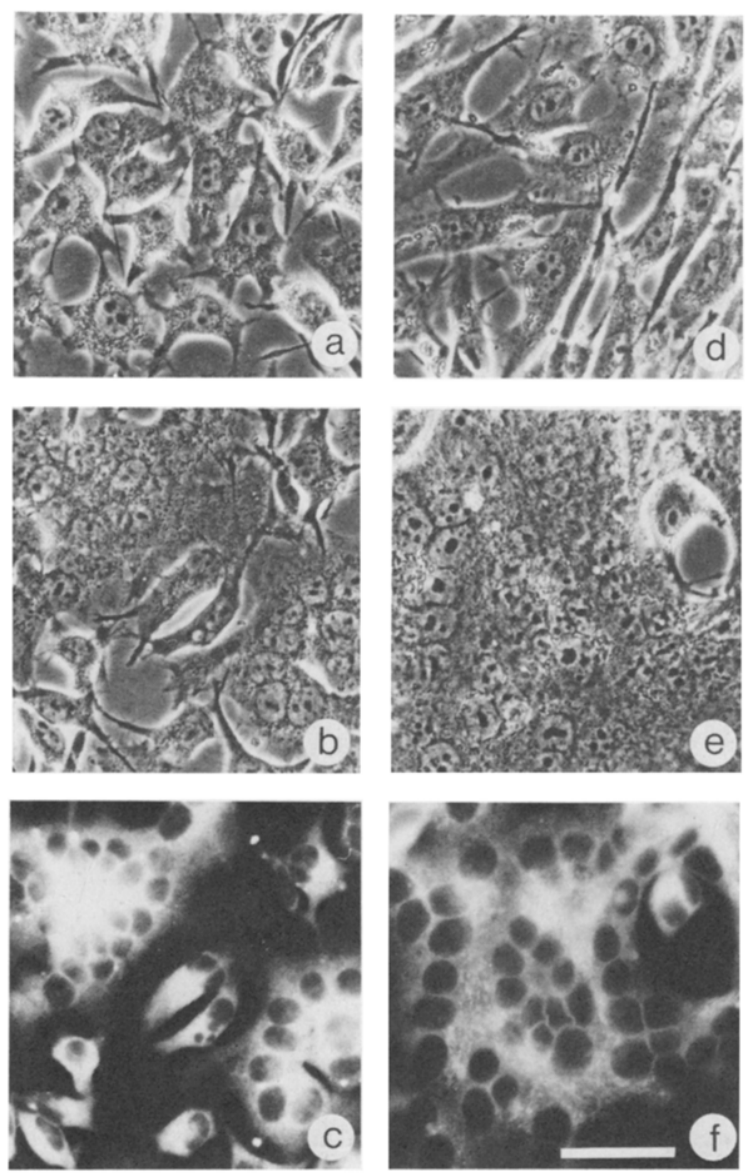

Fig. 2. Monolayer cells and homokaryons of the investigated cell lines: (a) L-cells; (b) L-homokaryons (after polyethyleneglycol-induced cell fusion); (c) same homokaryons as in (b), stained with the voltage-sensitive dye $\operatorname{diBA}-\mathrm{C}_{4}-(3)^{-} ;$(d) BICR/M1R- $k$ cells; (e) BICR/M1R- $k$ homokaryons (after polyethyleneglycol-induced cell fusion); (f) same homokaryons as in (e), stained with the voltage-sensitive dye $\operatorname{diBA}^{-\mathrm{C}_{4}-(3)^{-}}$. Bar: $50 \mu \mathrm{m}$.

units. After changing the potential to about -90 $\mathrm{mV}$, the fluorescence signal reduced its intensity within 20 min to about 20 units. Reduction of the potential to $-65 \mathrm{mV}$ was followed by a slight increase in fluorescence intensity which reached a plateau value within $11 \mathrm{~min}$. After this time the homokaryon's membrane potential was no more than $-3 \mathrm{mV}$, which corresponded to a fluorescence signal of about 80 units after another 20 min. A similar experiment is shown in Fig. 4 where the potential of a L-homokaryon was first changed from $-18 \mathrm{mV}$ to $-55 \mathrm{mV}$ and after $21 \mathrm{~min}$ to

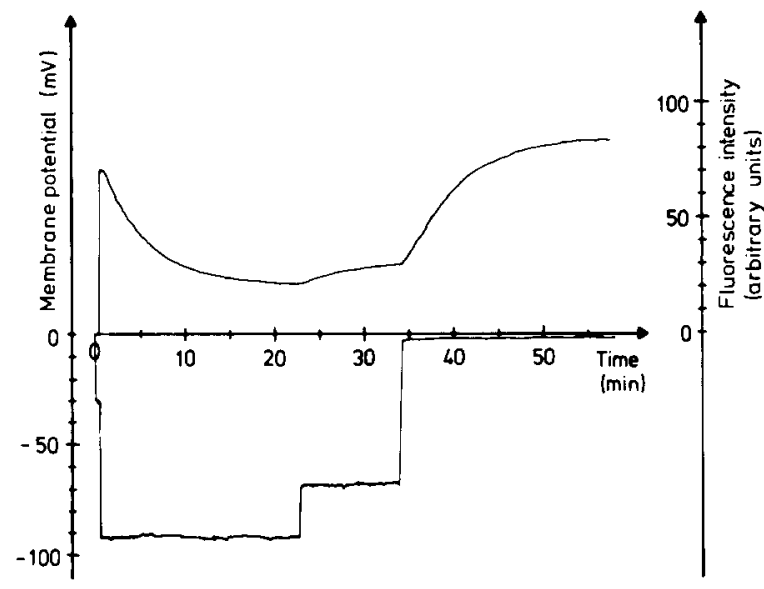

Fig. 3. Change in fluorescence intensity after different voltage steps in a L-homokaryon with nine nuclei, stained with $1 \mu \mathrm{M}$ diBA- $\mathrm{C}_{4}-(3)^{-}$in phosphate-buffered saline.

$-92 \mathrm{mV}$. The fluorescence signal responded by reducing its intensity with a similar time-course as that for the depolarizing experiment.

The smaller a voltage clamp step was, the longer it took to resolve the fluorescence signal.

Even the relatively slow oscillations of the membrane potential which occur regularly in homokaryons [13] could not be followed with our set-up (see Fig. 5), whereas - in the same homokaryon - a decrease in fluorescence intensity was obtained by a longer-lasting hyperpolarization.

The velocity of the fluorescence change, however, is also dependent on cell size - at least for homokaryons of up to ten nuclei. The increase of

TABLE I

\section{GLASS MICROELECTRODE MEASUREMENTS}

Mean values \pm standard deviations of bicarbonate-induced changes of membrane potential in BICR/M1R- $k$ homokaryons and corresponding fluorescence intensity.

\begin{tabular}{llll}
\hline $\begin{array}{l}\text { BICR/M1R-k } \\
\text { homokaryons } \\
\text { in phosphate- } \\
\text { buffered saline }\end{array}$ & $\begin{array}{l}\text { Potential } \\
\text { difference } \\
(\mathrm{mV})\end{array}$ & $\begin{array}{l}\text { Fluorescence } \\
\text { intensity } \\
\text { (a.u. })\end{array}$ & $\begin{array}{l}\text { Number of } \\
\text { measurements } \\
\text { (impalements) }\end{array}$ \\
\hline $\begin{array}{c}\text { Without } \\
\text { bicarbonate }\end{array}$ & $35.62 \pm 3.14$ & $18.98 \pm 3.84$ & 50 \\
$+\begin{array}{c}5.5 \mathrm{mM} \\
\text { bicarbonate } \\
+44 \mathrm{mM} \\
\text { bicarbonate }\end{array}$ & $51.12 \pm 3.41$ & $16.84 \pm 2.90$ & 46 \\
\hline
\end{tabular}




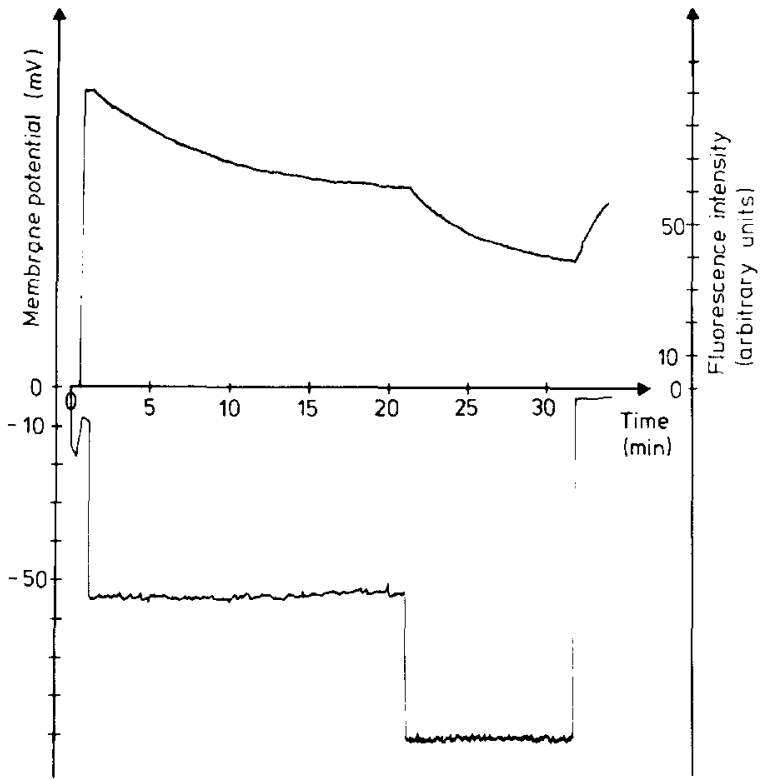

Fig. 4. Change in fluorescence intensity after different voltage steps in a L-homokaryon with ten nuclei, stained with $1 \mu \mathrm{M}$ diBA- $\mathrm{C}_{4}-(3)^{-}$in phosphate-buffered saline.

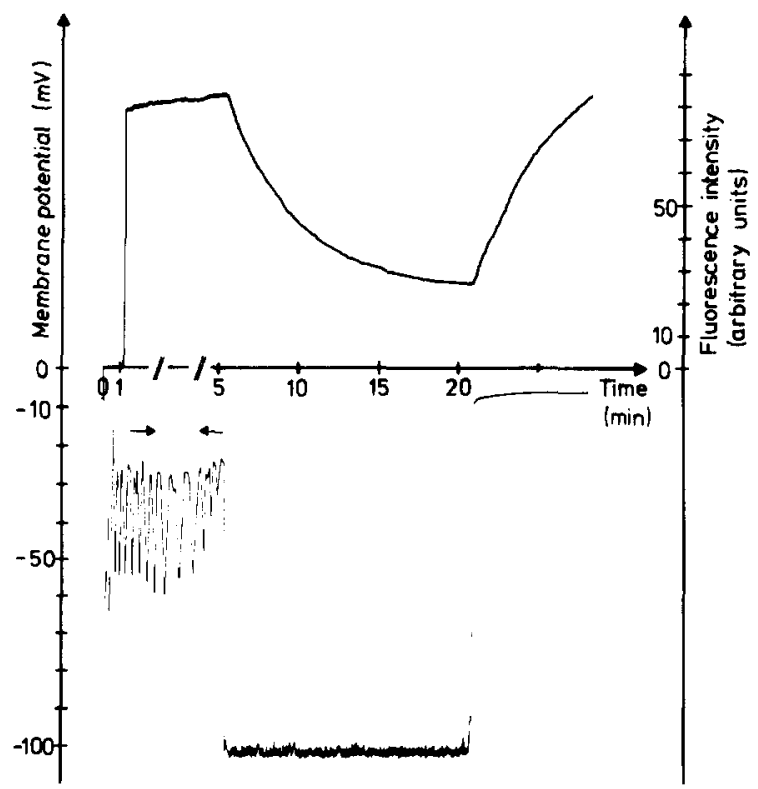

Fig. 5. Membrane-potential oscillations and a hyperpolarizing voltage step in an 11-nuclei L-homokaryon with simultaneous recording of fluorescence intensity. $1 \mu \mathrm{M}$ diBA- $\mathrm{C}_{4}-(3)^{-}$. Time scale changed where indicated by arrows.

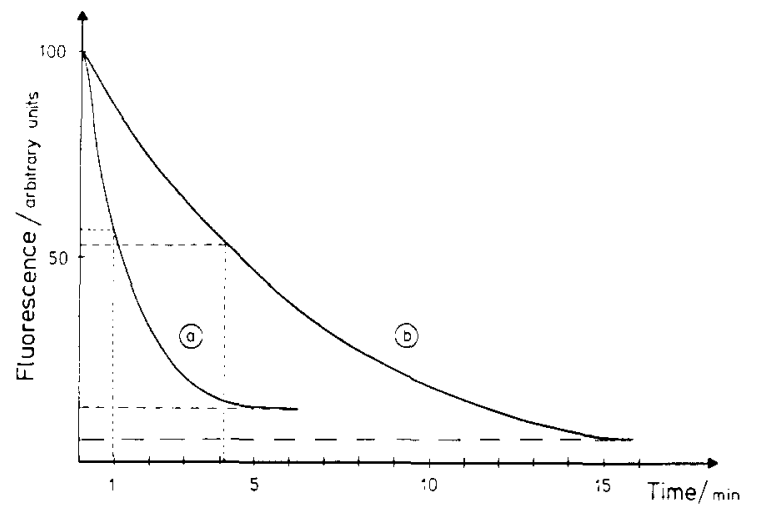

Fig. 6. Change in fluorescence intensity of a BICR/M1R- $k$ single cell (a) and a 21-nuclei homokaryon (b) of the same cell line under a hyperpolarizing voltage step of about $70 \mathrm{mV}$ (a) and about $80 \mathrm{mV}$ (b), respectively. $2 \mu \mathrm{M}$ diBA- $\mathrm{C}_{4}{ }^{-(3)^{-}}$in phosphate-buffered saline. Initial fluorescence intensity for both experiments: 100 arbitrary units.

surface and volume in larger homokaryons (over ten nuclei) exhibited no further significant influence on the time-course of the optical response. After a hyperpolarizing voltage step of about 70 $\mathrm{mV}$, a single BICR/M1R- $k$ cell reached its $50 \%$ level of total fluorescence change within $1 \mathrm{~min}$, whereas a homokaryon with 21 nuclei passed this level only after about $4 \mathrm{~min}$, even under slightly increased hyperpolarizing conditions of about 80 $\mathrm{mV}$ (see Fig. 6, initial fluorescence intensity for both experiments: 100 arbitrary units).

No difference in the fluorescence response, stated as the fractional change of fluorescence intensity per voltage change (see below) could be

\section{TABLE II}

SIGNAL SIZES AT DIFFERENT DYE CONCENTRATIONS FOR L- AND BICR/MIR- $k$ HOMOKARYONS (STATED AS FRACTIONAL CHANGE PER mV)

Mean values \pm standard deviations.

\begin{tabular}{lll}
\hline Cells & $\begin{array}{l}\text { Concentration of } \\
\text { diBA-C } 4^{-}(3)^{-} \\
(\mu \mathrm{M})\end{array}$ & $\left(\mathrm{d} F / F_{0}\right) \cdot 100$ per $\mathrm{mV}$ \\
\hline $\mathrm{L}$ & 1.0 & $1.11 \pm 0.20$ \\
& 2.0 & $1.03 \pm 0.20$ \\
& 3.0 & $1.07 \pm 0.15$ \\
$\mathrm{BICR} / \mathrm{M} 1 \mathrm{R}-k$ & 2.0 & $1.02 \pm 0.24$ \\
\hline
\end{tabular}


detected between the single cell and the homokaryon.

\section{Size of fluorescence response}

The size of the optical signal can be evaluated by the quotient of the maximal change in fluorescence intensity $\mathrm{d} F$ and the initial fluorescence intensity $F_{0}$. Neither alteration of the dye concentration in the staining solution nor any species-specific effect of the two different cell lines seemed to have any influence on the fractional change per $\mathrm{mV}$ voltage change, as shown in Table II.

\section{Kinetics of fluorescence changes}

The time-course of the fluorescence changes after varying the potential resembled a first-order reaction with a steady state different from zero. The velocity of this reaction was independent of the direction of the applied voltage change. We assume the following mathematical expression:

$-\mathrm{d}\left(F_{\mathrm{t}}-F_{\mathrm{ss}}\right) / \mathrm{d} t=k\left(F_{\mathrm{f}}-F_{\mathrm{ss}}\right)$

where $F_{t}$, fluorescence intensity at time $t$ after setting a new potential; $F_{0}$, fluorescence intensity at time $0 ; F_{\mathrm{ss}}$, fluorescence intensity at steady state; $k$, velocity coefficient. Eqn. 1 describes the velocity of a reaction; it can be resolved and transformed to different analytical relations, which contain the reaction rate constant as a quantitative criterion for the fluorescence kinetics. By integration of Eqn. 1, The two following functions can be derived:

$$
\begin{aligned}
& \left(F_{t}-F_{\mathrm{ss}}\right)=\left(F_{0}-F_{\mathrm{ss}}\right)-k \int_{0}^{t}\left(F_{t}-F_{\mathrm{ss}}\right) \mathrm{d} t \\
& \ln \left(F_{t}-F_{\mathrm{ss}}\right)=-k t+\ln \left(F_{0}-F_{\mathrm{ss}}\right)
\end{aligned}
$$

Our experimental data were evaluated by a multiparameter analysis, which has already proven its validity with different systems $[14,15]$. An example for the analysis of a hyperpolarizing experiment with an L-homokaryon is given in Fig. 7.

The data fit the predicted linear relationship according to Eqns. 2 and 3. The slopes of these straight lines represent the rate constant of a firstorder reaction. Therefore our assumption (Eqn. 1) is valid.

The values of the rate constant varied between 0.1 and $0.8 \mathrm{~min}^{-1}$ mainly depending on the cell size but also on the applied voltage step (see Table III), however, they were independent of the dye concentration (1-3 $\mu \mathrm{M})$ and the direction of voltage changes.

\section{TABLE III}

DEPENDENCE OF RATE CONSTANT $k$ ON HOMOKARYON SIZE AND VOLTAGE STEP SIZE FOR BICR/M1R- $k$ AND L

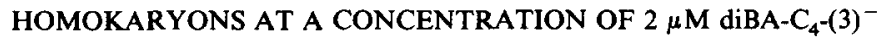

\begin{tabular}{lllllll}
\hline Cells & $\begin{array}{l}\text { Resting } \\
\text { potential } \\
(\mathrm{mV})\end{array}$ & $\begin{array}{l}\text { Voltage } \\
\text { clamp } \\
\text { potential } \\
(\mathrm{mV})\end{array}$ & $\begin{array}{l}\text { Voltage } \\
\text { step } \\
(\mathrm{mV})\end{array}$ & $\begin{array}{l}\text { Number } \\
\text { of } \\
\text { nuclei }\end{array}$ & $\begin{array}{l}\text { Rate } \\
\text { constant } k \\
\left(\mathrm{~min}^{-1}\right)\end{array}$ & $\begin{array}{l}\text { Signal } \\
\text { size } \\
\left(\mathrm{d} F / F_{0}\right) \cdot 100 \\
\text { per mV }\end{array}$ \\
\hline BICR/M1R-k & 25.0 & 94.5 & 69.5 & 1 & 0.818 & 0.86 \\
& 28.5 & 92.5 & 64.0 & 2 & 0.425 & 1.02 \\
& 53.0 & 93.5 & 40.5 & 2 & 0.332 & 1.62 \\
& 15.0 & 89.0 & 74.0 & 3 & 0.295 & 0.92 \\
& 21.0 & 94.0 & 71.0 & 4 & 0.320 & 0.97 \\
& 15.0 & 95.0 & 80.0 & 4 & 0.262 & 0.99 \\
& 22.0 & 90.5 & 68.5 & 6 & 0.188 & 1.02 \\
& 16.0 & 99.0 & 83.0 & 21 & 0.162 & 0.83 \\
& 28.8 & 62.1 & 33.3 & 6 & 0.145 & 1.12 \\
& 16.0 & 60.0 & 44.0 & 6 & 0.177 & 1.10 \\
& 42.0 & 88.0 & 46.0 & 6 & 0.201 & 1.35 \\
\end{tabular}




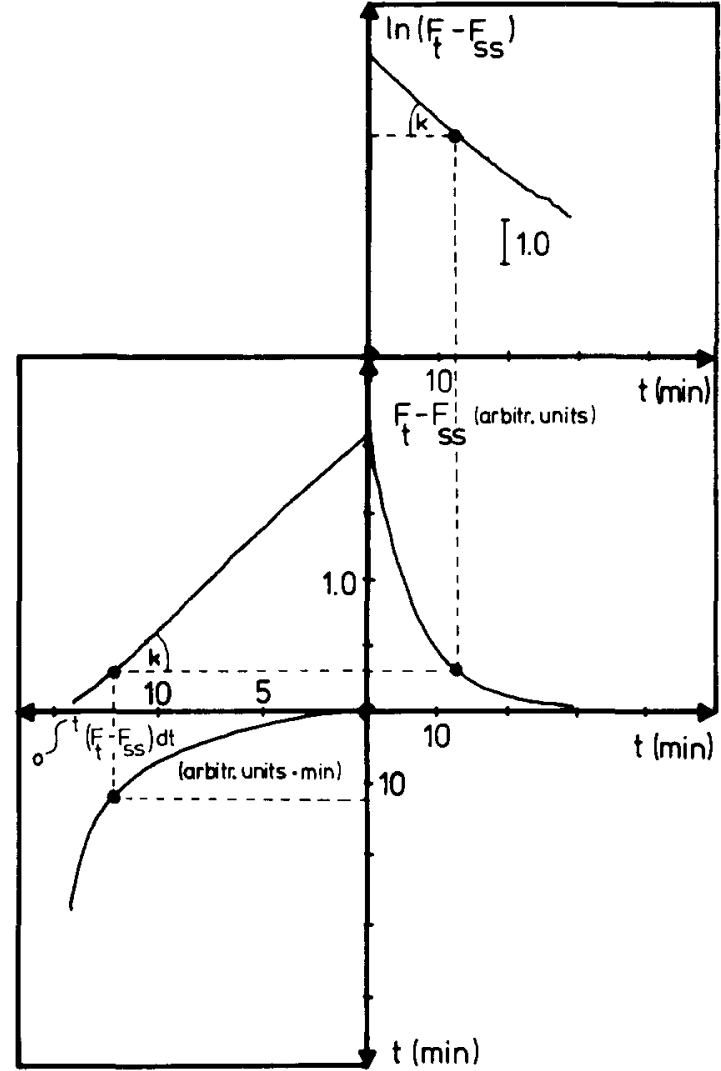

Fig. 7. Change of fluorescence intensity under a hyperpolarizing voltage step of about $80 \mathrm{mV}$ in a 17-nuclei L-homokaryon stained with $2 \mu \mathrm{M}$ diBA- $\mathrm{C}_{4}-(3)^{-}$. Multiparameter analysis of the kinetics, revealing a first-order reaction with a rate constant of $0.157 / \mathrm{min}$. For further details see text.

\section{Discussion}

Monolayer cells of BICR/M1R-k and L, stained with the negatively charged oxonol dye diBA- $\mathrm{C}_{4}$ $(3)^{-}$, respond to changes of membrane potential with significant fluorescence signals. Interestingly, only cytoplasmic components were stained with this dye (see Fig. 2), whereas the nuclei appeared unstained. Assuming a similar dye permeability for both plasma and nuclear membrane, the binding capacity of the dye molecules is different for cellular components in the cytoplasm and the nucleus, since the microelectrode-measured membrane potentials are similar in the cytoplasm and the nucleus [12]. For the positively charged cyanine dye diO- $\mathrm{C}_{6}-(3)^{+}$we found in some preliminary experiments the same staining pattern as for diBA-
$\mathrm{C}_{4^{-}}-(3)^{-}$. These results might be expected since both dyes should be similarly permeant because of their delocalized charge [6]. This cyanine dye, however, showed an insignificant response of its fluorescence signal to voltage changes, although Waggoner [6] assumed a similar reaction mechanism for both classes of dyes. The oxonol dye diBA- $\mathrm{C}_{4}$ (3) ${ }^{-}$, however, turned out to be a very useful probe for measuring the membrane potential in individual cells with a rather inexpensive optical instrumentation.

Our simultaneous measurements of membrane potentials with glass microelectrodes and fluorescence techniques were made possible by the use of homokaryons. In these polyethyleneglycol-fused giant cells the same potential difference is measured regardless of where the electrodes are inserted. For calibration of the fluorescent dyes and measurement of their kinetics, homokaryons allow insertion of two electrodes - for membrane potential measurement as well as for current injection and the simultaneous measurement of fluorescence intensity in a relatively large cytoplasmic area, which is undisturbed by the inserted electrodes. Since both electrically coupled and uncoupled homokaryons have unchanged membranes with regard to electrical and enzymatic properties [13] the results obtained with these giant cells may be extended to single cells.

In our experiments, the cells had been stained 30-45 min prior to the electrophysiological and optical measurements. This time was sufficient to allow a voltage-dependent distribution of the dye, as can be seen from the experiments in which voltage was changed.

In spite of the compartment-like staining of the cytoplasm a linear correlation between membrane potential and cytoplasmic fluorescence signal was measured which might partly be attributed to the integrating behaviour of the aperture in the focal plane of the real image of the object. Our direct calibration of monolayer cells confirms the indirect calibrations of suspended cells where the fluorescence of the supernatant or the suspension was determined. In these experiments, linear correlations between fluorescence intensities and calculated membrane potentials were also found, mainly for cyanine dyes, covering different potential ranges $[8,9,16]$. 
Determination of the kinetics of the fluorescence changes required stepwise voltage changes which were obtained by current injection. The slight fluctuations of the membrane potential after a stepwise change appeared to have a negligible effect on the fluorescence signal. Mathematical analysis of the fluorescence changes resulted in first-order kinetics, providing rate constants which allowed a quantitative comparison of different experimental conditions.

Variation of the dye concentration between 1 and $3 \mu \mathrm{M}$ had no influence on the velocity of the fluorescence change. With increasing voltage steps, increasing rate constants were obtained. The most significant influence on the rate constants, however, was the cell size (see Table III and Fig. 6): for similar voltage steps higher rate constants were always measured for single cells or small homokaryons.

The potential-dependent partition of charged dye molecules across a cell membrane follows a Nernst equation, the intracellular dye concentration, therefore, changes in a logarithmic function with the membrane potential. However, this must not necessarily result in a logarithmic response of the intracellular fluorescence signal.

Under our experimental conditions a significant fluorescence of the oxonol dye $\operatorname{diBA}-\mathrm{C}_{4}-(3)^{-}$was only measured with cell-associated dye molecules. Phosphate-buffered saline had only a faint fluorescence, whereas medium with calf serum showed an enhanced background fluorescence. This fluorescence is due to a binding of the dye molecules to serum proteins as is shown in Table IV and Fig. 8. This binding of dye molecules to proteins causes a peak shift in both excitation and absorption spectra (see Fig. 9). A similar increase in fluorescence intensity has been described for the positively charged cyanine dye diO- $\mathrm{C}_{6}-(3)^{+}[9]$.

We can thus propose the following mechanism for the voltage-sensitive reaction of the oxonol dye diBA-C $4^{-}(3)^{-}$(Scheme I). The cell membrane (M) is permeable for the dye molecule which binds to intracellular proteins $(\mathrm{P})$. The membrane potential determines the constant $k(\psi)$ which describes the equilibrium between the free dye inside $\left(A_{\text {in }}\right)$ and outside $\left(A_{\text {out }}\right)$ the cell. Therefore, the amount of protein-bound dye is indirectly dependent on the potential. The equilibrium between the dye-protein

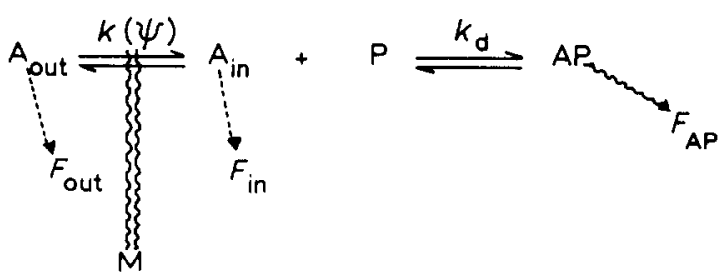

Scheme 1 .

complex (AP) and the free dye molecules in the cell is characterized by the dissociation constant $\left(k_{\mathrm{d}}\right)$ of the complex. The more negative the membrane potential, the smaller the concentration of the free dye in the cell, the fewer molecules bind, resulting in a reduced fluorescence intensity and vice versa. The fluorescence intensity of the free dye molecules inside $\left(F_{\text {in }}\right)$ and outside $\left(F_{\text {out }}\right)$ the cell is considerably less than that $\left(F_{\mathrm{AP}}\right)$ of protein-bound dye molecules. Affinity of dye molecules to intracellular proteins as well as their dissociation constant should be similar for both giant and small cells of the same strain. However, giant cells change their fluorescence intensity after changing the voltage with a significantly lower rate constant than smaller cells do. The velocity of the fluorescence change, therefore, must be dependent on an additional parameter: the total transmembrane transport. Since it is known that many mem-

\section{TABLE IV}

\section{INCREASE OF FLUORESCENCE INTENSITY}

Intensity in arbitrary units, registered at $563 \mathrm{~nm}$, excited at 495 $\mathrm{nm}$, upon addition of bovine $\gamma$-globulins, bovine serum albumin and calf serum to a $2 \mu \mathrm{M}$ solution of $\operatorname{diBA}-\mathrm{C}_{4^{-}}(3)^{-}$in phosphate-buffered saline.

\begin{tabular}{llll}
\hline & \multicolumn{2}{l}{ Intensity } & \\
\cline { 2 - 4 } & $\begin{array}{l}\text { Bovine } \\
\gamma \text {-globulins }\end{array}$ & $\begin{array}{l}\text { Bovine } \\
\text { serum albumin }\end{array}$ & $\begin{array}{l}\text { Calf } \\
\text { serum }\end{array}$ \\
\hline $\begin{array}{l}\text { Phosphate- } \\
\text {-buffered }\end{array}$ & & & \\
saline & 0 & 0 & 0 \\
(without & & & \\
dye) & & & \\
$0 \%$ & 1.00 & 1.00 & 1.00 \\
$0.25 \%$ & 2.77 & 8.94 & 3.25 \\
$0.50 \%$ & 4.26 & 11.04 & 5.48 \\
$1.00 \%$ & 7.28 & 12.20 & 8.76 \\
$2.50 \%$ & 13.72 & - & 12.19 \\
\hline
\end{tabular}




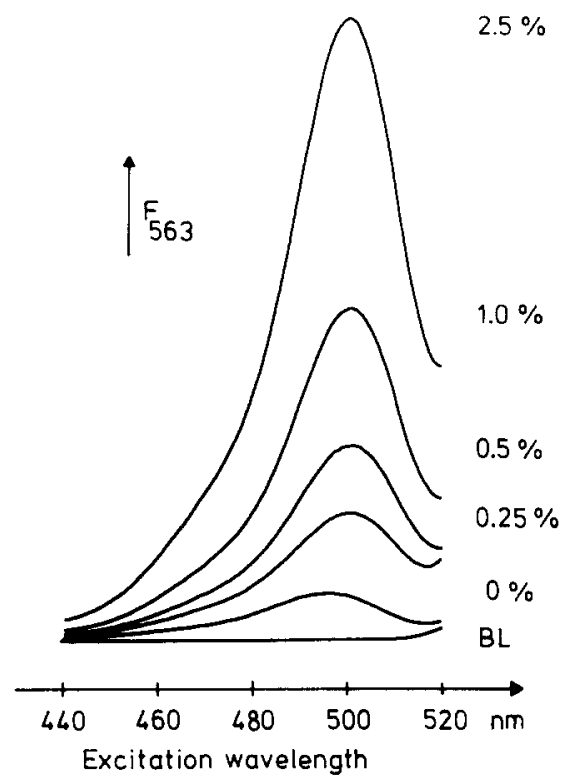

Fig. 8. Increase of fluorescence intensity (measured at $563 \mathrm{~nm}$ ) and peak shift of the excitation spectra upon addition of $\gamma$-globulins $(0.25 \% ; 0.5 \% ; 1.0 \% ; 2.5 \%)$ to a $2 \mu \mathrm{M}$ solution of diBA-C $_{4}-(3)^{-}$in phosphate-buffered saline. BL, baseline (phosphate-buffered saline only).

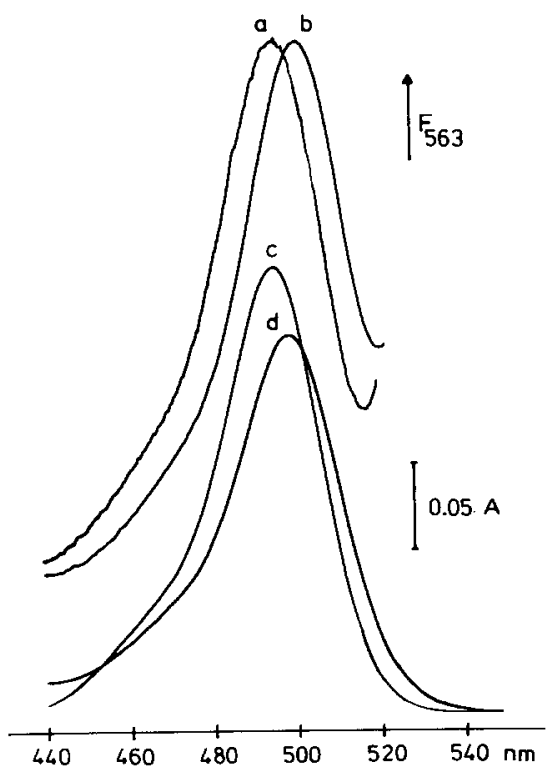

Fig. 9. Comparison of the excitation (top) and absorption (bottom) spectra of the fluorescent dye diBA- $\mathrm{C}_{4}-(3)^{-}(2 \mu \mathrm{M})$ in phosphate buffered saline without (a, c) and with $2.5 \% \quad \gamma$ globulins (b, d). The excitation spectra (a, b), measured at 563 $\mathrm{nm}$, are normalized to the same peak value. brane properties are similar for single cells and homokaryons [13], the conclusion can be drawn that the limiting factor for the transmembrane transport is the product of the surface/volume ratio and the concentration gradient of the dye across the membrane. With increasing cell size, the membrane surface area per unit volume is reduced according to a hyperbolic function. This can explain our observation that the measured rate constants of the fluorescence decay depend on the cell size. This kind of information could only be obtained by using homokaryons which were selected for different cell sizes.

\section{Acknowledgements}

We thank Drs. A.S. Waggoner and L.M. Loew for the gift of voltage-sensitive dyes. The technical assistance of Mrs. U. Lauterwasser is gratefully acknowledged.

\section{References}

1 Hamill, O.P., Marty, A., Neher, E., Sakmann, B. and Sigworth, F.J. (1981) Pflügers Arch. 391, 85-100

2 Cohen, L.B., Hille, B. and Keynes, R.D. (1968) Nature 218, 438-441

3 Cohen, L.B., Salzberg, B.M., Davila, H.V., Ross, W.N., Landowne, D., Waggoner, A.S. and Wang, C.H. (1974) J. Membrane Biol. 19, 1-36

4 Waggoner, A.S. (1979) Annu. Rev. Biophys. Bioeng. 8, 47-68

5 Freedman, J.C. and Larris, P.C. (1981) Int. Rev. Cytol. 12, $177-246$

6 Waggoner, A.S. (1976) J. Membrane Biol. 27, 317-334

7 Sims, P.J., Waggoner, A.S., Wang, C.H. and Hoffman, J.F. (1974) Biochemistry 13, 3315-3330

8 Hoffman, J.F. and Larris, P.C. (1974) J. Physiol. 239, $519-552$

9 Burckhardt, G. (1977) Biochim. Biophys. Acta 468, 227-237

10 Frank, W., Ristow, H.W. and Schwalb, S. (1972) Exp. Cell Res. 70, 390-396

11 Krähling, H., Schinkewitz, U., Barker, A. and Hülser, D.F. (1978) Cytobiology 17, 51-61

12 Hülser, D.F. (1971) Pflügers Arch. 325, 174-187

13 Hülser, D.F. and Lauterwasser, U. (1982) Exp. Cell Res. $139,63-70$

14 Sigrist, H., Allegrini, P.R., Strasser, R.J. and Zahler, P. (1980) in The Blue Light Syndrome (Senger, H., ed.), pp. 30-37, Springer Verlag, Berlin

15 Strasser, R.J. (1981) in Photosynthesis III (Akoyunoglou, G., ed.), pp. 727-737, Balaban International Science Services, Philadelphia, PA

16 Philo, R.D. and Eddy, A.A. (1978) Biochem. J. 174, 801-810 